\title{
Plasma neutrophil gelatinase associated lipocalin (NGAL) is associated with kidney function in uraemic patients before and after kidney transplantation
}

Nils E Magnusson ${ }^{1,2^{*}}$, Mads Hornum ${ }^{3}$, Kaj Anker Jørgensen ${ }^{4}$, Jesper Melchior Hansen ${ }^{5}$, Claus Bistrup ${ }^{6}$, Bo Feldt-Rasmussen ${ }^{3}$ and Allan Flyvbjerg ${ }^{1,2}$

\begin{abstract}
Background: Neutrophil gelatinase associated lipocalin (NGAL) is a biomarker of kidney injury. We examined plasma levels of NGAL in a cohort of 57 kidney allograft recipients (Tx group, $39 \pm 13$ years), a uraemic group of 40 patients remaining on the waiting list (47 \pm 11 years) and a control group of 14 healthy subjects matched for age, sex and body mass index (BMI). The kidney graft recipients were studied at baseline before transplantation and 3 and 12 months after transplantation and the uraemic group at baseline and after 12 months.

Methods: NGAL was measured using a validated in-house Time-Resolved Immuno-flourometric assay (TRIFMA). Repeated measurements differed by $<10 \%$ and mean values were used for statistical analyses. Spearman rank order correlation analysis and the Kruskal-Wallis non-parametric test were used to evaluate the association of NGAL concentrations with clinical parameters.

Results: Plasma NGAL levels before transplantation in the Tx and uraemic groups were significantly higher than in the healthy controls $(1,251 \mu \mathrm{g} / \mathrm{L}, 1,478 \mu \mathrm{g} / \mathrm{L}$ vs. $163 \mu \mathrm{g} / \mathrm{L}, \mathrm{p}<0.0001)$. In the Tx group NGAL concentrations were associated with serum creatinine $(R=0.51, p<0.0001)$, duration of end-stage renal failure $(R=0.41, p=0.002)$ and leukocyte count $(R=0.29, p<0.026)$. At 3 and 12 months plasma NGAL concentrations declined to $223 \mu \mathrm{g} / \mathrm{L}$ and $243 \mu \mathrm{g} / \mathrm{L}$, respectively and were associated with homocysteine $(R=0.39, p=0.0051$ and $R=0.47, p=0.0007)$.

Conclusions: Plasma NGAL is a novel marker of kidney function, which correlates to duration of end-stage renal failure (ESRD) and serum creatinine in uraemic patients awaiting kidney transplantation. Plasma NGAL is associated with homocysteine in transplanted patients. The prognostic value of these findings requires further studies.
\end{abstract}

\section{Background}

Neutrophil gelatinase associated lipocalin (NGAL) also known as Lipocalin 2 or Lcn 2 is a $25 \mathrm{kDa}$ protein identified originally as a protein associated with matrix metalloproteinase 9 (MMP-9) of human neutrophils [1]. Lipocalins are extracellular proteins which share a common tertiary structure that forms a barrel-like hydrophobic ligand binding site [2]. When bound to MMP-9, NGAL protects it from proteolytic degradation sustaining

\footnotetext{
* Correspondence: nm@farm.au.dk

${ }^{1}$ The Medical Research Laboratories, Faculty of Health Sciences, Aarhus University, Aarhus, Denmark

Full list of author information is available at the end of the article
}

the proteolytic activity of MMP-9. No specific receptor for NGAL has yet been identified. However, the endocytosis low density lipoprotein receptor Megalin has been shown to bind NGAL with high affinity suggesting that NGAL is taken up by host cells [3]. NGAL has been suggested as a bacteriostatic agent indicating involvement of NGAL in the innate immune response [4-7]. Moreover, serum levels of NGAL have been reported to be useful in discriminating between acute bacterial and viral infections [8]. Expression of NGAL is prominent in secondary granules of human neutrophils $[9,10]$. NGAL is induced by bacterial lipopolysaccharides [11], dexamethasone $[12,13]$, growth factors and cytokines such as insulin-like

\section{Biomed Central}


growth factor I (IGF-I) $[12,14]$ and interleukin 1 (IL-1) [15-18]. Upon nephrotoxic and/or ischemic injury NGAL levels are highly increased in kidney cortical tubules, blood and urine [18]. In vascular smooth muscle cells NGAL expression is induced in response to vascular injury and depends on nuclear factor kappa B (NF-kB) expression [19]. Interestingly, the interaction of NGAL with MMP-9 may be a mechanism by which the proteolytic activity of MMP-9 is modulated in the vascular repair process indicating a role for NGAL in cardiovascular disease (CVD). Expression of NGAL is induced upon activation of Toll-like receptors (TLRs) on immune cells constituting an acute phase response to infection [20]. NGAL has received considerable attention due to its role as an early biomarker in kidney disease [21-23]. In a cross-sectional study of 100 kidney allograft recipients serum NGAL was shown to correlate with kidney function [24] and it has been studied in several clinical settings of acute kidney injury (AKI) [25-30]. Haase et al. [26] confirmed the predictive and prognostic value of NGAL as an early biomarker for AKI in a meta-analysis involving 19 studies ( > 2,500 patients). Induction of NGAL after kidney injury precedes the elevation of classical markers for kidney damage $[27,28]$, e.g. serum creatinine, urinary $\mathrm{N}$-acetyl glucosamidase and $\beta 2$-microglobulin levels. In studies of renal failure in mice the functional significance of up-regulation of NGAL has been suggested to be renal protective $[18,31]$. The present study aimed to investigate the possible relationship between plasma NGAL levels and clinical parameters in a prospective study of non-diabetic uraemic patients.

\section{Methods \\ Study procedure}

The study population consisted of 97 non-diabetic uraemic patients and was based on a prospective, observational, national multicenter study. Data on the study population has been published previously [32]. In brief, 57 of the patients were scheduled for living donor kidney transplantation in the period between January 2006 and March 2008 at the four Danish transplantation centres: Rigshospitalet, Skejby, Odense, and Herlev University Hospitals (Tx group, age $39 \pm 13$ years). A control group of 40 patients from the transplantation waiting list at Rigshospitalet and Herlev University Hospitals (uraemic group, age $47 \pm 11$ ) was included. The study also included a group of healthy controls $(n=14)$. The healthy controls were BMI and sex matched and was recruited from public announcing. The regional ethical committee (\# KF 01279825) and The Data Protection Agency (\#2006-41-5640) approved the study. Participants gave their informed written consent. Transplanted participants were examined before transplantation and 3 and 12 months after transplantation. The uraemic controls were examined at baseline and 12 months later. The examinations were done after an overnight fast including coffee, tobacco, and exercise absence for 10 hours. Anti-hypertensive medication was allowed in the morning. A 75-gram oral glucose tolerance test (OGTT) was performed on all patients according to the WHO/ADA 2007 criteria [33]. An insulin sensitivity index was calculated according to Matsuda et al. [34]. Immunosuppression varied to some extent between the centers. Induction therapy included basiliximab (Simulect; Novartis), daclizumab (Zenapax; Roche), or antithymocyte globulin (Thymoglobulin; Genzyme B.V.). The majority of patients received 100-500 mg of intravenous methylprednisolone preoperatively, and treatment with oral prednisolone was started by $20-100 \mathrm{mg} / \mathrm{d}$ and was tapered to a dose of $7.5-10 \mathrm{mg}$ at 3 months and to $5-7.5 \mathrm{mg}$ at $9-12$ months. Rejection episodes, indicated by increased plasma creatinine of $20 \%$ or greater for 2 days, or biopsy proven, were treated with intravenous methylprednisolone, 500 mg, for 3-5 days. For each patient the accumulated corticosteroid dose within the first 90 days was calculated and given in equivalents of prednisolone dose in grams. Fortythree patients started on cyclosporine (Sandimune Neoral; Novartis) at a dose of $2.5-6 \mathrm{mg} / \mathrm{kg}$ twice daily tapered to a trough level of whole-blood concentration of 150-300 $\mu \mathrm{g} /$ $\mathrm{L}$ for the first 3 months and $100-150 \mu \mathrm{g} / \mathrm{L}$ thereafter. The remaining 14 patients started on tacrolimus (Prograf; Astellas) at a dose of $0.075-0.15 \mathrm{mg} / \mathrm{kg}$ twice daily tapered to a whole-blood concentration of $8-15 \mu \mathrm{g} / \mathrm{L}$ for the first 3 months and 5-10 $\mu \mathrm{g} / \mathrm{L}$ thereafter. A few patients $(\mathrm{n}=8)$ changed from one treatment modality to another during the course of the study, and two patients were changed to rapamycin (Rapamune; Wyeth) treatment.

After 10 minutes of rest in the supine resting position arterial blood pressure (BP) was measured in triplicate from the arm opposite to a fistula or dialysis catheter. Mean arterial BP (MAP) was calculated on the basis of these three measurements. Renal function was estimated by the Cockcroft-Gault formula (eGFR) [35]. Fasting blood samples were drawn from an antecubital vein and aliquots of EDTA-plasma were stored at $-80^{\circ} \mathrm{C}$. Examiners were blinded with regards to the clinical and metabolic status of patients and clinical information was analyzed and described after completion of the data collection. Anti-hypertensive treatment mainly included $\beta$-blockade, calcium channel blockade, angiotensin-II-blockade and diuretics. Anti-hypertensive medication was stopped at the time of transplantation and thereafter titrated aiming a BP below 130/80 $\mathrm{mmHg}$. Clinical characteristics of the study group are shown in Table 1.

\section{Statistical methods}

Data analyses using clinical data were performed using Statistical Analysis Software $\left(\mathrm{SAS}^{\circledR}\right)$ version 9.1. Unless specified otherwise, continuous data is described as mean 
Table 1 Demographic and clinical data, from 57 kidney allograft recipients (Tx group), 40 uraemic patients (uraemic controls) and 14 healthy controls, at baseline before transplantation.

\begin{tabular}{|c|c|c|c|}
\hline & $\begin{array}{c}\text { Tx-group } \\
\mathrm{N}=57\end{array}$ & $\begin{array}{c}\text { Uraemic group } \\
\qquad \mathrm{N}=40\end{array}$ & $\begin{array}{l}\text { Healthy controls } \\
\qquad \mathrm{N}=14\end{array}$ \\
\hline Age (years, SD) & $39 \pm 13$ & $47 \pm 11$ & $39 \pm 11$ \\
\hline Gender (male/female) & $38 / 19$ & $27 / 13$ & 5-Sep \\
\hline ESRD duration (months, range) & $24(0-134)$ & $45(1-168)$ & - \\
\hline $\mathrm{BMI}\left(\mathrm{kg} / \mathrm{m}^{2}\right)$ & $24 \pm 4$ & $24 \pm 4$ & $24 \pm 3$ \\
\hline Waist-hip ratio & $0.92 \pm 0.09$ & $0.91 \pm 0.08$ & $0.81 \pm 0.08^{* * *}$ \\
\hline Ever Smoking, n (\%) & $27(47)$ & $26(65)$ & $9(64)$ \\
\hline \multicolumn{4}{|l|}{ Diagnoses n (\%) } \\
\hline Glomerulonefritis & $28(49)$ & $13(33)$ & - \\
\hline Hypertensive & $5(9)$ & $11(28)$ & - \\
\hline \multicolumn{4}{|l|}{ Kidney disease } \\
\hline Vasculitis & $1(2)$ & $1(3)$ & - \\
\hline PKD & $3(5)$ & $7(18)$ & - \\
\hline Other/unknown & $20(35)$ & $8(20)$ & - \\
\hline Apoplexi & $3(5)$ & $3(8)$ & - \\
\hline Former transplanted & $11(19)$ & $10(25)$ & - \\
\hline \multicolumn{4}{|l|}{ Dialysis-status } \\
\hline $\mathrm{HD}$ & $28(49)$ & $28(70)$ & - \\
\hline CAPD & $19(33)$ & $9(27)$ & - \\
\hline Pre-dialysis & $10(18)$ & $3(8)$ & - \\
\hline First degree relatives with DM & $2(4)$ & $4(10)$ & $2(14)$ \\
\hline Fasting p-glucose (mmol/L) & $5.1 \pm 0.5$ & $5.1 \pm 0.5$ & $5.0 \pm 0.3$ \\
\hline P-glucose at 2-hours (mmol/L) & $7.4 \pm 1$ & $7.5 \pm 2$ & $5.4 \pm 1^{* * *}$ \\
\hline HbA1c (\%) & $5.2 \pm 0.4$ & $5.2 \pm 0.4$ & $5.2 \pm 0.2$ \\
\hline Insulin sensitivity index & $6.8 \pm 4.0$ & $7.9 \pm 5.1$ & $14.7 \pm 7.0^{* * *}$ \\
\hline Insulin secretion index & $36.9 \pm 18.5$ & $31.4 \pm 17.3$ & $27 \pm 14$ \\
\hline Systolic BP (mmHg) & $142 \pm 21$ & $141 \pm 24$ & $118 \pm 10^{* * *}$ \\
\hline Diastolic BP (mmHg) & $85 \pm 13$ & $83 \pm 14$ & $73 \pm 8^{* * *}$ \\
\hline Pulse & $69 \pm 11$ & $72 \pm 11$ & $61 \pm 10^{* * *}$ \\
\hline
\end{tabular}

Data are presented as mean \pm SD or median and range, numbers (n) and percent (\%). HD: hemodialysis, CAPD: continuous ambulatory peritoneal dialysis, ESRD: end stage renal disease, Tx: transplantation, PKD: polycystic kidney disease, DM: diabetes mellitus, BP: blood pressure. Wilcoxon Rank Sum Test or two sample ttest used where appropriate to test: uraemic patients vs. Healthy controls; ${ }^{*} p<0.05$, ${ }^{* *} p<0.005,{ }^{* * *} p<0.0005$.

$\pm \mathrm{SD}$ for normal distributions, and median and range for skewed distributions. Paired data within groups were compared by t-tests for normally distributed data, and group comparisons of continuous data were performed using two-sample t-test for normally distributed data and non-parametric Wilcoxon Rank Sum Test for not-normal distributed data. Chi squared or Fisher's exact tests were used for group comparisons between categorical data. Correlation analysis was done using Spearman Rank Analysis. Scatter plot, regression analysis and difference vs. average plots were performed using STATA version 11.1. P-values below 0.05 for parametric and non-parametric tests were considered significant.

\section{NGAL assay procedure}

Plasma NGAL levels were determined using stored EDTAplasma by an in-house time resolved immunofluorometric (TRIFMA) sandwich-type assay based on anti-NGAL antibodies and recombinant NGAL from R\&D Systems (Abingdon, UK). Microtitre plates (Nunc, Roskilde, Denmark) were coated overnight at $4^{\circ} \mathrm{C}$ with monoclonal capture NGAL antibody dissolved in phosphate buffered saline (PBS). Plates were blocked for 2 hours at room temperature with assay buffer $(1 \%(\mathrm{w} / \mathrm{v})$ BSA and $0.05 \%(\mathrm{v} / \mathrm{v})$ Tween 20 in PBS) and washed three times with $0.05 \%(\mathrm{v} / \mathrm{v})$ Tween 20 in PBS (PBST). Standards were prepared using recombinant NGAL by serial dilutions of up to three decades. A pool of plasma from five healthy adult donors and plasma pool spiked with recombinant NGAL were included as internal controls. Between each step of the assay the plates were washed three times with PBST. Samples and controls were diluted 1:200 in assay buffer and incubated overnight at $4^{\circ} \mathrm{C}$. Plates were then incubated with biotinylated monoclonal NGAL antibody in assay buffer and then incubated with streptavidin-europium (Perkin Elmer Life Sciences, Finland). Enhancement solution 
(Perkin Elmer Life Sciences) was added and plates were measured in a time-resolved fluorometer. Standards, samples and non-specific binding were analysed in duplicate. Non-specific background (NSB) averaged 5000 counts per second (cps), the lowest standard $8000 \mathrm{cps}$ and the highest standard $1.4 \times 10 \mathrm{E} 06 \mathrm{cps}$. The detection limit was estimated at $<0.1 \mu \mathrm{g} / \mathrm{L}$ based on NSB $+3 \mathrm{SD}$. The coefficient of variation $(\mathrm{CV})$ within assays of standards controls and unknown samples averaged less than $7 \%$ based on repetitive runs of identical plasma samples. The CV between assays was determined by repetitive analysis of standards and control samples. After 15 different runs the between assay CVs averaged $<12 \%$. Repetitive freezing and thawing of plasma from the healthy donors was tested every other cycle up to eleven cycles and did not alter the levels of NGAL significantly (data not shown) in line with previously published data [36]. The linearity of the assay, estimated with plasma samples using serial dilutions up to 1:800 indicated a high precision over a wide range of concentrations (mean $\mathrm{CV}=4.4 \%$, range; 0.5-9\%). Minor increases of NGAL levels was found with increasing dilutions in samples with high levels of NGAL ( > $1400 \mu \mathrm{g} / \mathrm{L}$, $\mathrm{CV}=8 \%)$.

\section{Recovery of recombinant NGAL}

Recovery was based on plasma samples containing high, medium or low levels of NGAL. These samples were spiked with different amounts of exogenously added recombinant NGAL and diluted 1:200 to a final concentration of 3, 9 or $30 \mu \mathrm{g} / \mathrm{L}$ of recombinant NGAL. Samples without added NGAL were used as controls. The assay was analyzed with six replicates and repeated twice. For each sample the recovery was estimated as the mean percentage of the measured concentrations compared to the expected concentrations.

\section{Comparison between platforms}

The in-house NGAL assay was compared back to back with a commercially available ELISA kit (036, Bioporto Diagnostics, Gentofte, Denmark) with samples of plasma and serum; 34 uraemic plasma samples and a collection of 33 serum samples were run on both platforms. The ELISA assay was recently validated [36]. The ELISA kit

Table 2 Kidney allograft recipient patients vs. waiting list patients and within groups ${ }^{*} p<0.05, * * p<0.0005$, all patients vs. healthy controls ${ }^{\S \S} p<0.0005$ (students paired t-test).

\begin{tabular}{cccc}
\hline & Tx group & Waiting list & Healthy \\
\hline NGAL $\mu \mathrm{g} / \mathrm{L}$ & $1,251 \pm 438$ & $1,478 \pm 403^{*}$ & $163 \pm 29^{\S \S \S}$ \\
Time $=0$ & & & \\
\hline NGAL $\mu \mathrm{g} / \mathrm{L}$ & $243 \pm 86^{* * *}$ & $1,668 \pm 496$ & - \\
Time $=12$ months & & & \\
\hline
\end{tabular}

analysis was carried out as suggested by the manufacturer. Samples used for the in-house NGAL assay were prepared and diluted 1:200 as described above. The assays were performed on the same day to minimize day to day variation.

\section{Results}

The relationship between plasma NGAL and clinical characteristics

NGAL data were not normally distributed and Spearman rank order correlation analysis and the KruskalWallis non-parametric test were used to evaluate the association of NGAL concentrations with clinical parameters. In the Tx group mean NGAL levels were 1,251 $\pm 438 \mu \mathrm{g} /$ $\mathrm{L}$ prior to $\mathrm{Tx}($ time $=0)$ vs. $223 \pm 110 \mu \mathrm{g} / \mathrm{L}(\mathrm{p}<0.001)$ and $243 \pm 86 \mu \mathrm{g} / \mathrm{L}(\mathrm{p}<0.001)$ at 3 and 12 months post $\mathrm{Tx}$, respectively, compared to $163 \pm 29 \mu \mathrm{g} / \mathrm{L}$ in the healthy controls (Tx-group at time $=0$ vs. healthy, $\mathrm{p}<0.0005$ ). Mean NGAL levels are shown in Table 2. Following transplantation the NGAL levels were significantly reduced, but remained above the levels found in the healthy controls $(243 \pm 86 \mu \mathrm{g} / \mathrm{L}$ vs. $163 \pm 29 \mu \mathrm{g} / \mathrm{L}, \mathrm{p}<0.0001) . \mathrm{NGAL}$ levels in the uraemic group remaining on the waiting list were significantly higher than in the Tx group at baseline before transplantation $(1,478 \pm 403 \mu \mathrm{g} / \mathrm{L}$ vs. $1,251 \pm 438$ $\mu / \mathrm{L}, \mathrm{p}<0.05)$ and may probably be explained by a significant higher mean age and duration of ESRD in the uraemic group ( 47 vs. 39 years, and 45 vs. 24 months) and hence differences in serum creatinine. There was no significant difference in NGAL levels between the groups when stratifying for OGTT status, immunosuppression treatment or age in the Tx group (data not shown).

\section{Relationship between NGAL and kidney function}

Before Tx plasma NGAL concentrations were highly associated with serum creatinine $(\mathrm{R}=0.51, \mathrm{p}<0.0001)$ and leukocyte count $(\mathrm{R}=0.29, \mathrm{p}<0.026)$ in concordance with previously published data $[21,26,37]$. At three and 12 months post Tx NGAL levels were associated with homocysteine $(\mathrm{R}=0.39, \mathrm{p}=0.005$ and $\mathrm{R}=0.47, \mathrm{p}=0.0007)$ and at 12 months the association with leukocyte count was mitigated reflecting the partially restored kidney function. The relationship between NGAL levels and serum creatinine is shown in Figure 1.

We found no relationship between NGAL levels and increased blood pressure defined as systolic BP $>130$ $\mathrm{mmHg}$ and/or diastolic $\mathrm{BP} \geq 90 \mathrm{mmHg}$ in either groups both before and after transplantation. However, eGFR was significantly lower in the hypertension group after 12 months $(\mathrm{eGFR}=71 \pm 26$ versus eGFR $=84 \pm 18, \mathrm{p}<0.05)$.

\section{Recovery of recombinant NGAL}

The median recovery of exogenously added recombinant NGAL in plasma was $90 \%$ for samples spiked to $3 \mu \mathrm{g} / \mathrm{L}$, 


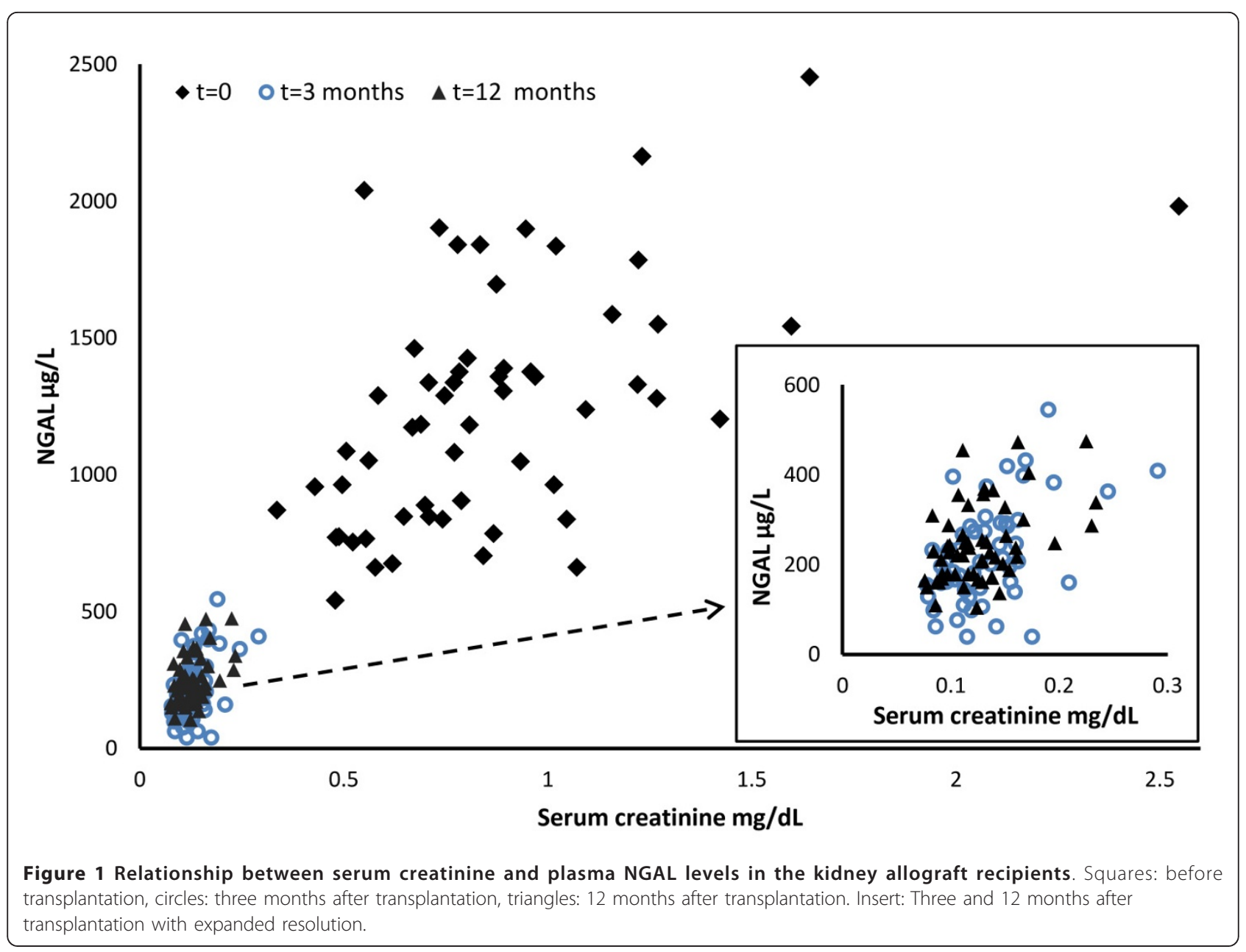

97\% for samples with $9 \mu \mathrm{g} / \mathrm{L}$ and $89 \%$ for samples with $30 \mu \mathrm{g} / \mathrm{L}$. The overall median recovery was $91 \%$. The results are shown in Table 3.

\section{Comparison between platforms}

Two samples were omitted from the analysis due to high standard deviations ( $>15 \%$ ) in the in-house assay and 16 samples were out of range ( $>900 \mu \mathrm{g} / \mathrm{L})$ in the ELISA assay and were omitted. These samples were re- measured, and confirmed (average CV 6\%, range; 4-7\%), with the in-house assay in four serial dilutions (up to $1: 800$ ) (data not shown). For the in-house assay the concentrations of NGAL ranged between $83 \mu \mathrm{g} / \mathrm{L}$ and 563 $\mu \mathrm{g} / \mathrm{L}$ with mean $215 \mu \mathrm{g} / \mathrm{L}$. For the ELISA, concentrations ranged between $57 \mu \mathrm{g} / \mathrm{L}$ and $496 \mu \mathrm{g} / \mathrm{L}$ with mean $186 \mu \mathrm{g} / \mathrm{L}$. The two methods were compared using scatter plot, regression analysis and a Bland-Altman plot [38], Figure 2. The Bland-Altman plot shows a random

Table 3 Recovery of NGAL, internal replicates $(n=6)$, external replicates $(n=2)$

\begin{tabular}{|c|c|c|c|c|}
\hline NGAL level in sample & Spike $\mu \mathrm{g} / \mathrm{L}$ & Expected $\mu \mathrm{g} / \mathrm{L}$ & Measured $\mu \mathrm{g} / \mathrm{L}$ & Recovery (\%) \\
\hline \multirow[t]{3}{*}{ Low } & 3 & 3.8 & 3.8 & 99.9 \\
\hline & 9 & 9.8 & 9.9 & 100.8 \\
\hline & 30 & 30.8 & 27.4 & 89.1 \\
\hline \multirow[t]{3}{*}{ Medium } & 3 & 9.8 & 8.1 & 82.9 \\
\hline & 9 & 15.8 & 15.0 & 94.6 \\
\hline & 30 & 36.8 & 31.9 & 86.6 \\
\hline \multirow[t]{3}{*}{ High } & 3 & 11.5 & 9.9 & 86.2 \\
\hline & 9 & 17.5 & 16.4 & 94.1 \\
\hline & 30 & 38.5 & 34.8 & 90.6 \\
\hline
\end{tabular}




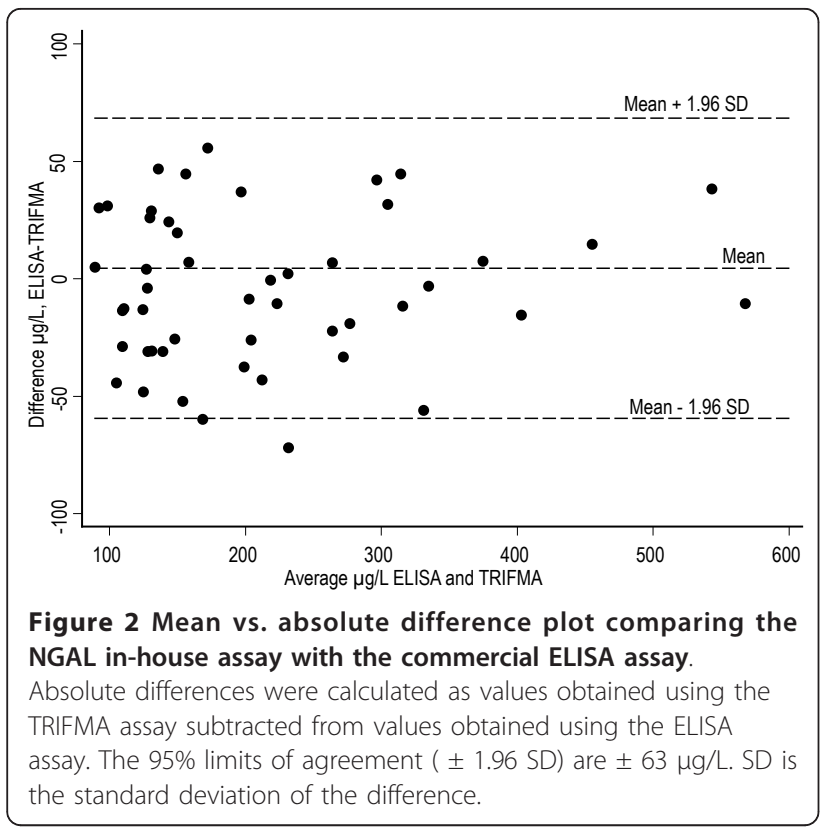

distribution around the mean with a proportional difference of approximately $14 \%$ on average with higher levels reported by the TRIFMA assay. The result of a Pitman's test showed that there was no significant difference $(\mathrm{p}=$ 0.55 ) between the measuring errors of the two methods. Regression analysis, shown in Figure 3, yielded an $R$ value of 0.96 . Taken together these data indicate a high concordance between the assays.

\section{Discussion}

This prospective study investigated the level of plasma NGAL in a cohort of kidney allograft recipients and included a uraemic control group and a group of healthy controls. The main findings of this study were that plasma NGAL levels were markedly higher in



Figure 3 Scatter plot; TRIFMA assay NGAL levels vs. ELISA assay NGAL levels (linear regression: $R=0.96$ ). patients prior to transplantation compared to the levels measured at three and twelve months after transplantation. Plasma NGAL levels remained constant between three and twelve months but was still significantly higher than the level in the healthy control group reflecting that the kidney function is not fully restored as seen by lowered eGFR. In the Tx-group before transplantation we found that NGAL paralleled measures of kidney function and correlated to serum creatinine and leukocyte count confirming previous reports showing that elevated levels of NGAL reflect dysfunction of the kidney $[21,26,37,39]$. At three and twelve months after transplantation we found that high plasma NGAL levels were associated with elevated plasma homocysteine which may illustrate the atherosclerotic component of kidney disease. Patients with chronic kidney disease (CKD) (within stage 3 CKD category) have an increased risk above $20 \%$ by the Framingham risk score for developing cardiovascular disease (CVD) [40,41]. A recent study reported significant associations between plasma NGAL, plasma homocysteine, eGFR and serum creatinine in patients with advanced carotid atherosclerosis [42] highlighting the hypothesis of NGAL as a mediator of vascular remodeling and potential role in CVD $[43,44]$. The relevance of this association for the present study is unresolved, but raises the question of a possible relationship between homocysteine and NGAL since homocysteine is a known risk factor of CVD [45]. There was no clear relationship between NGAL and BP in the Tx-group prior to transplantation or in the uraemic group (remaining on the waiting list for one year). Several studies have reported an association between NGAL and BP. First, Eleneihoum et al. reported an association between NGAL and diastolic blood pressure in middle aged patients with early asymptomatic atherosclerosis [43]. Secondly, Bolignano et al. found association between NGAL and systolic BP in patients with congestive heart failure [43]. Thirdly, Malyszko et al. showed association of NGAL to hypertension in patients with stable coronary artery disease and normal kidney function [46] and found an association in renal allograft recipients in a cross-sectional study [24]. Finally, Giaginis et al. reported association between NGAL and hypertension in a patient group with carotid atherosclerosis [42]. In most of these studies BP was also associated to eGFR, serum creatinine or both. In the study of Giaginis et al., hypertensive patients presented with increased serum creatinine levels and reduced eGFR indicating that the association between NGAL and hypertension may be secondary to the effect of renal impairment. The reason why we did not find any association between $\mathrm{BP}$, NGAL and serum creatinine, both before and three and 12 months post-Tx may be due to the limited size of our cohort. However, high BP was associated with 
reduced eGFR at twelve months, supporting the idea that NGAL is secondary to eGFR in terms of BP.

A limitation of our study is that we included a rather small group of patients in CKD stage 5 (eGFR $<15 \mathrm{ml}$ / $\mathrm{min}$ ), but paired longitudinal data were available to compensate for this. Also, the uraemic control group consists of older patients and with longer duration of uraemia. The use of serum creatinine and eGFR values in uraemic patients is biased and influenced by dialysis, weight and muscles of the patient and should be interpreted with caution.

\section{Conclusions}

Plasma NGAL correlated to serum creatinine, eGFR and duration of ESRD and to serum creatinine and eGFR after transplantation. Moreover, plasma NGAL was associated with homocysteine after transplantation. It remains to be clarified whether the association between NGAL and homocysteine is caused by presently unknown factors or may be due to a further extension of the atherosclerotic component of kidney disease.

\section{Acknowledgements}

We gratefully acknowledge Joan Hansen, The Medical Research Laboratories, Institute of Clinical Medicine, Faculty of Health Sciences, Aarhus University Hospital, for technical assistance.

\section{Author details \\ ${ }^{1}$ The Medical Research Laboratories, Faculty of Health Sciences, Aarhus University, Aarhus, Denmark. ${ }^{2}$ Department of Endocrinology and Internal Medicine, Aarhus University Hospital, Aarhus, Denmark. ${ }^{3}$ Department of Nephrology, Copenhagen University Hospital, Rigshospitalet, Copenhagen, Denmark. ${ }^{4}$ Department of Renal Medicine C, Aarhus University Hospital, Skejby, Denmark. ${ }^{5}$ Department of Nephrology, Copenhagen University Hospital,Herlev Hospital, Copenhagen, Denmark. ${ }^{6}$ Department of Nephrology, Odense University Hospital, Odense, Denmark.}

\section{Authors' contributions}

NEM and AF conceived the study. NEM was responsible for the assay design, measurements of NGAL, statistical analyses and for writing the paper $\mathrm{MH}$ was responsible for the statistical analyses involving clinical data. $\mathrm{MH}$ $\mathrm{KAJ}, \mathrm{JMH}, \mathrm{CB}$ and $\mathrm{BFR}$ were responsible for the prospective study used for these analyses. All authors' contributed to the manuscript. All authors have read and approved the final manuscript.

The results presented in this paper have not been published previously in whole or part, except in abstract form.

\section{Competing interests}

The authors declare that they have no competing interests.

Received: 8 July 2011 Accepted: 10 February 2012

Published: 10 February 2012

\section{References}

1. Kjeldsen $L$, Johnsen $A H$, Sengelov $H$, Borregaard $N$ : Isolation and primary structure of NGAL, a novel protein associated with human neutrophil gelatinase. J Biol Chem 1993, 268(14):10425-10432.

2. Patel RC, Lange D, McConathy WJ, Patel YC, Patel SC: Probing the structure of the ligand binding cavity of lipocalins by fluorescence spectroscopy. Protein Eng 1997, 10(6):621-625.

3. Hvidberg V, Jacobsen C, Strong RK, Cowland JB, Moestrup SK, Borregaard N: The endocytic receptor megalin binds the iron transporting neutrophil- gelatinase-associated lipocalin with high affinity and mediates its cellular uptake. FEBS Lett 2005, 579(3):773-777.

4. Goetz DH, Holmes MA, Borregaard N, Bluhm ME, Raymond KN, Strong RK: The Neutrophil Lipocalin NGAL is a Bacteriostatic Agent that Interferes with Siderophore-Mediated Iron Acquisition. Mol Cell 2002, 10(5):1033, 1043..

5. Yang J, Mori K, Li JY, Barasch J: Iron, lipocalin, and kidney epithelia. Am J Physiol Renal Physiol 2003, 285(1):F9-18.

6. Berger T, Togawa A, Duncan GS, Elia AJ, You-Ten A, Wakeham A, Fong HE, Cheung CC, Mak TW: Lipocalin 2-deficient mice exhibit increased sensitivity to Escherichia coli infection but not to ischemia-reperfusion injury. Proc Natl Acad Sci USA 2006, 103(6):1834-1839.

7. Flo TH, Smith KD, Sato S, Rodriguez DJ, Holmes MA, Strong RK, Akira S, Aderem A: Lipocalin 2 mediates an innate immune response to bacterial infection by sequestrating iron. Nature 2004, 432(7019):917-921.

8. Xu SY, Pauksen K, Venge P: Serum measurements of human neutrophil lipocalin (HNL) discriminate between acute bacterial and viral infections. Scand J Clin Lab Invest 1995, 55(2):125-131.

9. Axelsson L, Bergenfeldt M, Ohlsson K: Studies of the release and turnover of a human neutrophil lipocalin. Scand I Clin Lab Invest 1995, 55(7):577-588.

10. Seveus L, Amin K, Peterson CG, Roomans GM, Venge P: Human neutrophil lipocalin (HNL) is a specific granule constituent of the neutrophil granulocyte. Studies in bronchial and lung parenchymal tissue and peripheral blood cells. Histochem Cell Biol 1997, 107(5):423-432.

11. Sunil VR, Patel KJ, Nilsen-Hamilton M, Heck DE, Laskin JD, Laskin DL: Acute endotoxemia is associated with upregulation of lipocalin $24 \mathrm{p} 3 / \mathrm{Lcn} 2$ in lung and liver. Exp Mol Pathol 2007, 83(2):177-187.

12. Liu M, Prisco M, Drakas R, Searles D, Baserga R: 24p3 in Differentiation of Myeloid Cells. J Cell Physiol 2005, 205(2):302-309.

13. Garay-Rojas E, Harper M, Hraba-Renevey S, Kress M: An apparent autocrine mechanism amplifies the dexamethasone- and retinoic acid-induced expression of mouse lipocalin-encoding gene 24p3. Gene 1996, 170(2):173-180.

14. Sorensen OE, Cowland JB, Theilgaard-Monch K, Liu L, Ganz T, Borregaard N: Wound healing and expression of antimicrobial peptides/polypeptides in human keratinocytes, a consequence of common growth factors. J Immunol 2003, 170(11):5583-5589.

15. Jayaraman A, Roberts KA, Yoon J, Yarmush DM, Duan X, Lee K, Yarmush ML: Identification of neutrophil gelatinase-associated lipocalin (NGAL) as a discriminatory marker of the hepatocyte-secreted protein response to IL-1beta: a proteomic analysis. Biotechnol Bioeng 2005, 91(4):502-515.

16. Cowland JB, Sorensen OE, Sehested M, Borregaard N: Neutrophil gelatinase-associated lipocalin is up-regulated in human epithelial cells by IL-1 beta, but not by TNF-alpha. J Immunol 2003, 171(12):6630-6639.

17. Pawluczyk IZ, Furness PN, Harris KP: Macrophage-induced rat mesangial cell expression of the 24p3-like protein alpha-2-microglobulin-related protein. Biochim Biophys Acta 2003, 1645(2):218-227.

18. Mori K, Lee HT, Rapoport D, Drexler IR, Foster K, Yang J, Schmidt-Ott KM, Chen X, Li JY, Weiss S, Mishra J, Cheema FH, Markowitz G, Suganami T, Sawai K, Mukoyama M, Kunis C, D'Agati V, Devarajan P, Barasch J: Endocytic delivery of lipocalin-siderophore-iron complex rescues the kidney from ischemia-reperfusion injury. J Clin Invest 2005, 115(3):610-621.

19. Bu DX, Hemdahl AL, Gabrielsen A, Fuxe J, Zhu C, Eriksson P, Yan ZQ: Induction of neutrophil gelatinase-associated lipocalin in vascular injury via activation of nuclear factor-kappaB. Am J Pathol 2006, 169(6):2245-2253.

20. Draper DW, Bethea HN, He YW: Toll-like receptor 2-dependent and -independent activation of macrophages by group $B$ streptococci. Immunol Lett 2006, 102(2):202-214.

21. Mishra J, Ma Q, Prada A, Mitsnefes M, Zahedi K, Yang J, Barasch J, Devarajan P: Identification of neutrophil gelatinase-associated lipocalin as a novel early urinary biomarker for ischemic renal injury. J Am Soc Nephrol 2003, 14(10):2534-2543.

22. Supavekin S, Zhang W, Kucherlapati R, Kaskel FJ, Moore LC, Devarajan P. Differential gene expression following early renal ischemia/reperfusion. Kidney Int 2003, 63(5):1714-1724.

23. Ichimura T, Hung CC, Yang SA, Stevens JL, Bonventre JV: Kidney injury molecule-1: a tissue and urinary biomarker for nephrotoxicant-induced renal injury. Am J Physiol Renal Physiol 2004, 286(3):F552-63. 
24. Malyszko J, Malyszko JS, Mysliwiec M: Serum neutrophil gelatinaseassociated lipocalin correlates with kidney function in renal allograft recipients. Clin Transplant 2009, 23(5):681-686.

25. Wagener G, Jan M, Kim M, Mori K, Barasch JM, Sladen RN, Lee HT: Association between increases in urinary neutrophil gelatinaseassociated lipocalin and acute renal dysfunction after adult cardiac surgery. Anesthesiology 2006, 105(3):485-491.

26. Haase-Fielitz A, Bellomo R, Devarajan P, Story D, Matalanis G, Dragun D, Haase M: Novel and conventional serum biomarkers predicting acute kidney injury in adult cardiac surgery-a prospective cohort study. Crit Care Med 2009, 37(2):553-560

27. Zappitelli M, Washburn KK, Arikan AA, Loftis L, Ma Q, Devarajan P, Parikh CR, Goldstein SL: Urine neutrophil gelatinase-associated lipocalin is an early marker of acute kidney injury in critically ill children: a prospective cohort study. Crit Care 2007, 11(4):R84.

28. Wheeler DS, Devarajan P, Ma Q, Harmon K, Monaco M, Cvijanovich N, Wong HR: Serum neutrophil gelatinase-associated lipocalin (NGAL) as a marker of acute kidney injury in critically ill children with septic shock. Crit Care Med 2008, 36(4):1297-1303.

29. Ling W, Zhaohui N, Ben H, Leyi G, Jianping L, Huili D, Jiagi Q: Urinary IL-18 and NGAL as early predictive biomarkers in contrast-induced nephropathy after coronary angiography. Nephron Clin Pract 2008, 108(3): c176-81.

30. Bachorzewska-Gajewska H, Malyszko J, Sitniewska E, Malyszko JS, Dobrzycki S: Neutrophil-gelatinase-associated lipocalin and renal function after percutaneous coronary interventions. Am J Nephrol 2006, 26(3):287-292.

31. Mishra J, Mori K, Ma Q, Kelly C, Yang J, Mitsnefes M, Barasch J, Devarajan P: Amelioration of ischemic acute renal injury by neutrophil gelatinaseassociated lipocalin. J Am Soc Nephrol 2004, 15(12):3073-3082.

32. Hornum M, Jorgensen KA, Hansen JM, Nielsen FT, Christensen KB, Mathiesen ER, Feldt-Rasmussen B: New-onset diabetes mellitus after kidney transplantation in Denmark. Clin J Am Soc Nephrol 2010, 5(4):709-716.

33. American Diabetes Association: Diagnosis and classification of diabetes mellitus. Diabetes Care 2011, 34(Suppl 1):S62-9.

34. Matsuda M, DeFronzo RA: Insulin sensitivity indices obtained from oral glucose tolerance testing: comparison with the euglycemic insulin clamp. Diabetes Care 1999, 22(9):1462, 1470.

35. Cockcroft DW, Gault MH: Prediction of creatinine clearance from serum creatinine. Nephron 1976, 16(1):31-41.

36. Pedersen KR, Ravn HB, Hjortdal VE, Norregaard R, Povlsen JV: Neutrophil gelatinase-associated lipocalin (NGAL): validation of commercially available ELISA. Scand J Clin Lab Invest 2010, 70(5):374-382.

37. Malyszko J, Malyszko JS, Bachorzewska-Gajewska H, Poniatowski B, Dobrzycki S, Mysliwiec M: Neutrophil gelatinase-associated lipocalin is a new and sensitive marker of kidney function in chronic kidney disease patients and renal allograft recipients. Transplant Proc 2009, 41(1):158-161.

38. Dewitte K, Fierens C, Stockl D, Thienpont LM: Application of the BlandAltman Plot for Interpretation of Method-Comparison Studies: A Critical Investigation of Its Practice. Clin Chem 2002, 48(5):799-801.

39. [http://www.ncbi.nlm.nih.gov/pubmed? term=smertaUsingngalasanearlydiagnostictestofacutekidney2011].

40. de Vinuesa SG, Ortega M, Martinez P, Goicoechea M, Campdera FG, Luno J: Subclinical peripheral arterial disease in patients with chronic kidney disease: prevalence and related risk factors. Kidney Int Supp/ 2005, 93(93): S44-7.

41. Parikh NI, Hwang SJ, Larson MG, Levy D, Fox CS: Chronic kidney disease as a predictor of cardiovascular disease (from the Framingham Heart Study). Am J Cardiol 2008, 102(1):47-53.

42. Giaginis C, Zira A, Katsargyris A, Klonaris C, Theocharis S: Clinical implication of plasma neutrophil gelatinase-associated lipocalin (NGAL) concentrations in patients with advanced carotid atherosclerosis. Clin Chem Lab Med 2010, 48(7):1035-1041.

43. Falke $P$, Elneihoum AM, Ohlsson K: Leukocyte activation: relation to cardiovascular mortality after cerebrovascular ischemia. Cerebrovasc Dis 2000, 10(2):97-101.

44. Forsblad J, Gottsater A, Persson K, Jacobsson L, Lindgarde F: Clinical manifestations of atherosclerosis in an elderly population are related to plasma neopterin, NGAL and endothelin-1, but not to Chlamydia pneumoniae serology. Int Angiol 2002, 21(2):173-179.
45. Castro R, Rivera I, Blom HJ, Jakobs C, Tavares de Almeida I: Homocysteine metabolism, hyperhomocysteinaemia and vascular disease: an overview. $J$ Inherit Metab Dis 2006, 29(1):3-20.

46. Malyszko J, Bachorzewska-Gajewska H, Malyszko JS, Pawlak K, Dobrzycki S: Serum neutrophil gelatinase-associated lipocalin as a marker of renal function in hypertensive and normotensive patients with coronary artery disease. Nephrology (Carlton) 2008, 13(2):153-156.

\section{Pre-publication history}

The pre-publication history for this paper can be accessed here: http://www.biomedcentral.com/1471-2369/13/8/prepub

doi:10.1186/1471-2369-13-8

Cite this article as: Magnusson et al:: Plasma neutrophil gelatinase associated lipocalin (NGAL) is associated with kidney function in uraemic patients before and after kidney transplantation. BMC Nephrology 2012 13:8.

\section{Submit your next manuscript to BioMed Central and take full advantage of:}

- Convenient online submission

- Thorough peer review

- No space constraints or color figure charges

- Immediate publication on acceptance

- Inclusion in PubMed, CAS, Scopus and Google Scholar

- Research which is freely available for redistribution

Submit your manuscript at www.biomedcentral.com/submit
Biomed Central 